\title{
Engaging Leaders Foster Employees' Well-Being at Work
}

\author{
Vivi Gusrini Rahmadani* ${ }^{1,2}$ and Wilmar B. Schaufeli ${ }^{1}$ \\ ${ }^{1}$ Research Unit Occupational \& Organizational Psychology and Professional Learning, KU Leuven, Belgium \\ ${ }^{2}$ Faculty of Psychology, Universitas Sumatera Utara, Indonesia
}

\begin{abstract}
This is a longitudinal study with one-year panel design and included 412 Indonesian employees from a state-owned company. The data was collected by a survey at time 1 (April-June 2017) and time 2 (April-July 2018) from participants who returned the questionnaire at both times. Structural Equation Modeling by Amos was performed to test the hypotheses. The result supported the hypotheses that engaging leadership at time 1 directly and positively predicted work engagement at time 2 , and indirectly via the fulfilling basic need satisfaction at time 1 (partial mediation). The model showed an acceptable fit with the data $(\chi 2=48.70, \mathrm{df}=32, \mathrm{p}<0.03$; RMSEA=0.03; SRMR= 0.01; CFI=0.99; TLI=0.98). The result suggests that employees' work-related basic needs are important to be fulfilled in order to increase their well-being namely, their work engagement, and engaging leaders have important part to satisfy those basic needs. Hence, it is suggested for companies or organizations to foster engaging leaders through leadership development programs.
\end{abstract}

Keywords: engaging leadership, basic need satisfaction, work engagement, longitudinal study

\section{Introduction}

Academics and professionals of work and organizational psychology have become increasingly interested in employees' optimal functioning and positive experiences at work including on how to prevent ill and increase well-being (Luthans, 2002). One of the most research frameworks studying of both health-impairment process and motivational process at work is Job Demands Resources Model (Demerouti et al., 2001; Schaufeli \& Bakker, 2004). According to JD-R Model, leadership is one of the unique antecedents that could stimulate both job resources and job demands and there is a need to integrate it in that framework (Schaufeli \& Bakker, 2010; Tims, Bakker, \& Xanthopoulou, 2011; Schaufeli, 2015). For example, leaders could be the sources of both support and stress to the employees. Leaders can positively influence their followers' health and well-being, both directly by the effect of the quality of their relationship and indirectly through their influence on the availability of job resources to their followers, including followers' work engagement (Breevaart, Bakker, Demerouti, \& van den Heuvel, 2015; Engelbrecht, Heine, \& Mahembe, 2017). This study will focus on the motivational process of JD-R Model with positive leadership as the main antecedent.

Leaders provide a resourceful work environment that fulfills followers' basic psychological needs, which in turn, enhances followers's well-being, namely work engagement (Breevaart et al., 2015). Schaufeli, Salanova, González-Romá, \& Bakker (2002), described engagement more specifically as “....a positive, fulfilling, workrelated state of mind that is characterized by vigor, dedication, and absorption" (p.74). Vigor refers to high levels of energy and perseverance, dedication to a sense of significance, inspiration, and involvement and absorption to being focused, fully concentrated and engrossed in one's work. Employees who feel engaged will fully dedicate themselves to the organization and do their job with great enthusiasm (Markos \& Sridevi, 2010); they are intrinsically motivated (Schaufeli, 2012), proactive (Schaufeli \& Salanova, 2008), and creative (Huhtala \& Parzefall, 2007), and also more healthy and committed to the organization (Halbesleben, 2010). Thus, there is a need for organizations to nurture engaged employees or foster employees' work engagement.

A recent, meta-analysis (DeCuypere \& Schaufeli, 2018) shows that various leadership styles are positively related to work engagement, such as ethical leadership $(\mathrm{k}=9 ; \rho=0.58)$, transformational leadership $(\mathrm{k}=36 ; \rho=$ 
$0.46)$, servant leadership ( $\mathrm{k}=3 ; \rho=0.43)$, authentic leadership $(\mathrm{k}=17 ; \rho=0.38)$, and empowering leadership ( $\mathrm{k}$ $=4 ; \rho=0.35)$. However, there is no specific leadership style that explicitly aim to increase work engagement. Schaufeli (2015) developed the concept of engaging leadership that is rooted in Self Determination Theory (SDT; Deci \& Ryan, 2000) and specifically to promote work engagement with certain leaders' behaviors. Building on Schaufeli's concept, this present study tries to fill the research gap by testing empirically an alternative leadership style that stimulating health and well-being, specifically to increase work engagement, that is engaging leadership. Thus, the current study investigates engaging leadership and its impact to work engagement among employees in Indonesia. In sum, the added value of this study is to explain the concurrent validity of engaging leadership regarding work engagement. Taken together the study will broaden our knowledge of leadership and work engagement in a non-western, Indonesian context.

\section{Engaging Leadership}

By employing engaged workers, organizations may increase not only the well-being of the employees, but also the performance. The performance is not only at the individual and team level, but also at the organization and business unit level (Salanova, Rodríguez-Sánchez, Schaufeli, \& Cifre, 2014; Schaufeli, 2012; Schneider, Barbera, \& Macey, 2009; Torrente, Salanova, Llorens, \& Schaufeli, 2012). Various studies were conducted in the last decade with almost the similar finding, that is, work engagement is beneficial to employees as well as for the organizations they work for. Schaufeli \& Bakker (2010) integrated work engagement in the Job Demands-Resources model explaining that work engagement mediates the impact of job resources and personal resources on personal and organizational outcomes. A resource that is studied as an antecedent of work engagement is leadership (Schaufeli, 2015). The reason for doing so is that leadership has an impact on other job resources, which, in their turn, drive work engagement.

The basic concept of engaging leadership is that engaging leaders satisfy employees' basic psychological needs, which, in their turn, increase their work engagement. According to SDT basic psychological needs are defined as "those nutriments that must be procured by a living entity to maintain its growth, integrity, and health" (Deci \& Ryan, 2000, p. 326). Three basic psychological needs are differentiated; the needs for autonomy, relatedness, and competence. The need for autonomy is defined as the individuals' desire to experience a sense of ownership over his or her own behavior. The need for relatedness described as the individuals' desire to be part of a group and to feel connected with other workers. Finally, the need for competence is the individuals' inherent desire to be effective in dealing with work challenges and being capable of accomplishing desired outcomes. In addition, a fourth basic psychological need was introduced namely the need for meaningfulness (Baumeister, 1991; Frankl, 1992), which defined as the individuals' inherent desire to be engaged in activities that are useful, important, significant, and are in line with their personal values (Schaufeli, 2015), in this case, the activities are their jobs. To conclude, the key to put employees towards full engagement is the fulfilling of their basic psychological needs by creating opportunities for need satisfaction (Meyer, Gagné, \& Parfyonova, 2012).

The concept of engaging leadership is rooted in SDT and explains that employees will engage when their basic psychological needs for autonomy, relatedness, competence, and meaningfulness are satisfied. Schaufeli (2015) argued that engaging leaders fulfill the basic psychological needs of their employees by performing certain leadership behaviors, namely strengthening, empowering, connecting, and inspiring. By empowering employees, for instance by encouraging team members to give their own opinion, engaging leaders satisfy their need for autonomy. By strengthening employees, for example through delegating tasks and responsibilities, engaging leaders satisfy their need for competence. By connecting employees with others in their team, engaging leaders satisfy the employee's need for relatedness. And finally, by inspiring employees, engaging leaders acknowledge their personal contribution to the significant overall goal of the team or organization and thus, satisfy their need for meaningfulness. Preliminary evidence from a study among 361 South African miners suggests that, indeed, the satisfaction of basic psychological needs mediates the relationship between engaging leadership and work engagement (De Beer \& Schaufeli, 2018). In addition, the study of Schaufeli (2015) 
suggests that engaging leaders increase levels of job resources which, in their turn, are positively associated with work engagement. To conclude this argument, the main objective of the present study is to connect the concept of engaging leadership to work engagement in an Indonesian sample and demonstrate its concurrent validity. Thus, we formulate:

Hypothesis: Engaging leadership at time 1 is positively related to work engagement at time 2 mediated by workrelated basic need satisfaction at time 1 .

\section{Method}

\section{Sample}

Employees working in different sites/units of an Indonesian state-owned agricultural company which mainly produces crude palm oil. In each unit, they worked to produce, manage, and market a specific agricultural commodity, such as palm oil tree, tea, cacao, rubber tree, and vegetables. The data used in this study were collected in two waves, on April-June 2017 and on April-July 2018. In 2017 we had 611 out of 700 participants (response rate 87.3 percent). In 2018 we had 465 out of 607 participants (response rate 71 percent, nested in 75 teams with team membership ranging from 6-8 employees). From 465 participants who returned the survey at time 2, 53 cases did not complete the data, thus they were dropped. Then, the data consisted of 412 employees who participated and completed the surveys at time 1 and time 2. All participants were males, working as bluecollar workers which means they have various operational position working directly in the plantation.

\section{Procedure}

The data were collected with an official agreement from the company in order to ensure the feasibility to conduct a longitudinal study with one-year time lag. This company is an Indonesian state-owned holding company which operates in the cultivation of palm oil and rubber, and the production, sale, and export of palm oil and rubber products. With over 100.000 employees spreading along its huge plantation area across big islands in Indonesia, we conveniently selected 700 participants, who located in Sumatra region. The surveys were handed in sealed envelopes to the participants in each unit by the appointed research assistants. Participants received a written description of the study along with an informed consent for the survey. The surveys were completed during the working hours of the participants, then, the completed survey were sent back in a sealed envelope to the research assistants collectively per unit via a distribution officer, within maximum of two weeks. Participants received a written description of the study along with an informed consent in the survey.

\section{Measurements}

Self-reported five-point Likert published scales were used in the current study ranging from 1 (never) to 5 (always) for all scales. All the items were translated into Bahasa Indonesia following the double translation procedure (Brislin, 1970).

The Engaging Leadership Scale (Schaufeli, 2015) was assessed the four core dimensions of engaging leadership, namely strengthening, connecting, empowering, and inspiring with three items each, therefore, there are 12 items in total. The sample item of strengthening was "My supervisor delegates tasks and responsibilities to team members", connecting was "My supervisor encourages collaboration among team members", empowering was "My supervisor gives team members enough freedom to complete their tasks", and inspiring was "My supervisor is able to enthuse team members with his/her plans". The value of Cronbach's alpha for this scale was 0.87 . 
Work engagement was assessed with the 9-item version of the Utrecht Work Engagement Scale (UWES, Schaufeli et.al, 2006). Previous studies carried out in other countries have shown that the UWES has satisfactory psychometric properties (Schaufeli, 2012). The UWES assesses the three core dimensions of work engagement, namely vigor, dedication, and absorption. A sample item of vigor was "At my work, I feel bursting with energy", dedication was "I am proud of the work that I do", and absorption was "I get carried away when I'm working. The value of Cronbach's alpha for this scale was 0.87 .

The Basic Psychological Need Satisfaction Scale was assessed the four components of basic psychological need satisfaction, namely the need for autonomy, relatedness, competence, and meaningfulness. The first three psychological needs are based on the adaption of Basic Need Satisfaction at Work Scale (Deci, et al., 2001) by Van den Broeck et.al (2008). The fourth need, meaningfulness, was added by Schaufeli (2015). All needs were measured with three items each: autonomy (e.g. "If I could choose, I would do things at work differently), competence (e.g. "I really master my tasks at my job"), relatedness (e.g. "I often feel alone when I am with my colleagues"), and meaningfulness (e.g. "My work is meaningful for me"). All 12 items use a five-point Likert scale ranging between "Strongly disagree" (1) to "Strongly agree" (5). The value of Cronbach's alpha for the total scale of basic need satisfaction was 0.79 .

\section{Results}

\section{Descriptive Statistics}

Data were analyzed using SPSS version 21. Table 1 presents the means, standard deviations, and correlation coefficients, and Cronbach Alpha's of the study variables. As expected, all variables were positively and significantly correlated.

Table 1. Means (M), Standard Deviations (SD), Correlation Coefficients of the Study Variables $(N=412)$

\begin{tabular}{llllll}
\hline Variables & Mean & SD & 1 & 2 & 3 \\
\hline Engaging Leadership T1 & 4.17 & 0.56 & 1 & $.374^{* *}$ & $.269^{* *}$ \\
\hline Basic Need Satisfaction T1 & 4.27 & 0.48 & $.374 * *$ & 1 & $.219^{* *}$ \\
\hline Work Engagement T2 & 4.48 & 0.38 & $.269 * *$ & $.219^{* *}$ & 1 \\
\hline
\end{tabular}

** Correlation is significant at the 0.01 level. The range of scale for all variables are 1-5.

\section{Testing of Hypothesis}

Structural Equation Modelling (SEM) as implemented by AMOS (Arbuckle, 1997) was conducted to test the research. Result shows that the research model fits the data well, with all fit indices meeting their respective criteria, and with all path coefficients being positively significant (see Figure 1). The model showed an acceptable fit with the data $(\chi 2=48.70, \mathrm{df}=32, \mathrm{p}<0.03$; RMSEA=0.03; SRMR=0.01; CFI=0.99; TLI=0.98). The result supported the hypothesis that engaging leadership at time 1 directly and positively predicted work engagement at time 2 , and indirectly via the fulfilling basic need satisfaction at time 1 (partial mediation). This model explains $55 \%$ of the variance.

Engaging leaders who strengthen, connect, empower, and inspire their employees, predicted the satisfaction of the employees' basic needs namely, need for competence, relatedness, and autonomy respectively. Thus, after the basic needs satisfied, the followers start to embrace the engagement state namely vigor, dedication, and absorption. These findings suggest that employees' basic needs are important to be fulfilled in order to increase their work engagement, and engaging leaders have the essential role to satisfy those basic needs. 


\section{Discussion}

This current study examined whether the impact of engaging leadership to future work engagement is mediated by basic psychological need satisfaction. By strengthening, connecting, empowering, and inspiring, engaging leaders satisfied the basic psychological needs of their employees namely, the need for autonomy, competence, relatedness, and meaningfulness. Subsequently, basic need satisfaction was, in its turn, positively related to work engagement in terms of vigor, dedication, and absorption. A structural equation modeling analyses provided a strong evidence for the validity of the research model that confirmed a mediating role of basic need satisfaction in the relationship between engaging leadership and work engagement over time. These findings are in line with previous studies that investigated the role of basic need satisfaction at work as the mediating variable in increasing well-being, such as work engagement (Deci, et.al, 2001; Van den Broeck, et al, 2008) and as the underlying mechanism on the relationship of engaging leadership and work engagement (Schaufeli, 2015; Rahmadani et al., 2019).

To conclude, this study makes two contributions to the work engagement and leadership literature. First, it supports Schaufeli's (2015) assumption about the mediating role of basic need satisfaction at work as the psychological underlying mechanism that might explain why engaging leadership might stimulate work engagement. Furthermore, this study confirmed the role of engaging leadership on work engagement over time. This research showed that engaging leadership is related to work engagement through the satisfaction of the basic psychological needs. Secondly, from the three original basic needs as postulated by SDT, one specific basic need was added, namely the need for meaningfulness. The current study showed that this particular need behaved, in a similar way as the other original SDT needs. Future research is suggested to replicate this research model in the various cross-national and cross-cultural context. In addition to that, intervention research is needed to test the effectiveness of this particular positive leadership style.

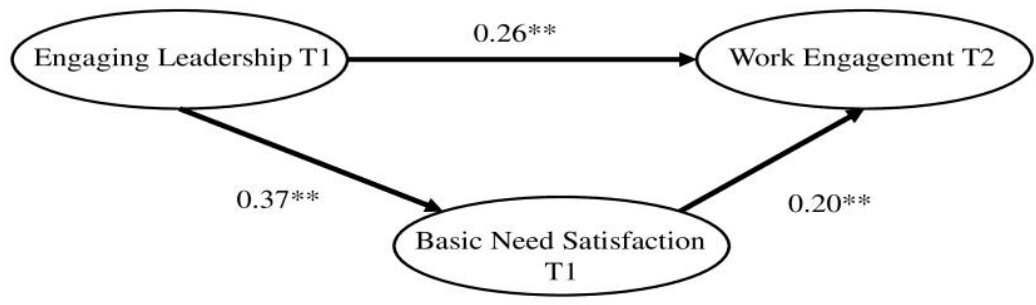

Figure 1. The role of engaging leadership at time 1 on employees' work engagement at time 2 mediated by work-related basic psychological need satisfaction at time $1(N=412)$.

\section{Limitations}

This study used self-report measures that may lead to the occurrence of common method bias such as social desirability bias. For instance, the measurement of engaging leadership was based on the perception of the followers. In the future studies, engaging leadership and work engagement could be measured with multimethod and multi-rater, such as using 360 degrees assessment (Mazetti, Schaufeli, Guglielmi, \& Depolo, 2016). 
The current study investigated engaging leadership, which is a novel construct. However, it cannot be dismissed that existing leadership concepts such as servant leadership or transformational leadership would yield similar results. Thus, in future research, studying engaging leadership together with other leadership styles to find their unique contribution was encouraged.

\section{Practical Implications}

Organizations may develop leadership programs for nurturing leaders (Shuck \& Herd, 2012), specifically to be engaging leaders. Leaders were encouraged to focus not only to the achievement of organizational goals but also to concern to the satisfaction of their followers' basic needs.

Satisfaction of employees' basic needs may become one of leaders' priorities as it leads to employees' engagement, and eventually, to employees' health and well-being at work. Thus, leaders may have an open conversation with their employees to determine their level of basic needs satisfaction. On the other hand, employees may aware that their health and well-being -to some degree- depends on their relationship with their leaders. Hence, employees also could be more receptive to the leaders' efforts to strengthen, empower, connect, and inspire them. For instance, they accept the task delegation from the leaders as it may fulfill their need for autonomy.

\section{Acknowledgement}

This research was funded by Indonesia Endowment Fund for Education (LPDP) Scholarship.

\section{References}

Arbuckle, J.L. 1997. Amos User's Guide Version 3.6. Chicago, IL: Smallwaters Corporation.

Breevaart, K., Bakker, A. B., Demerouti, E., \& van den Heuvel, M. 2015. Leader-member exchange, work engagement, and job performance. Journal of Managerial Psychology, 30, 754-77.

Brislin, R. W. 1970. Back-translation for cross-cultural research. Journal of Cross-Cultural Psychology, 1(3), $185-216$

Demerouti, E., Nachreiner, F., Bakker, A. B., \& Schaufeli, W. B. 2001. The job demands-resources model of burnout. Journal of Applied Psychology, 86, 499-512.

Deci, E., \& Ryan, R. 2000. The "what" and "why" of goal pursuits: Human needs and the self-determination of behavior. Psychological Inquiry, 11, 227-268.

Deci, E.L, Ryan, R.M, Gagné, M., Leone, D.R., Usunov, J. \& Kornazheva, B.P. 2001. Need satisfaction, motivation, and well-being in the work organizations of a former eastern bloc country: A cross-cultural study of self-determination. Personality and Social Psychology Bulletin, 27, 930-942.

DeCuypere, A., \& Schaufeli, W. 2018. Positive leadership styles and engagement: A meta-analysis and review. Manuscript Submitted for Publication.

Engelbrecht, A. S., Heine, G., \& Mahembe, B. 2017. Integrity, ethical leadership, trust and work engagement. Leadership \& Organization Development Journal, 38(3), 368-379.

Frankl, V. 1992. Meaning in industrial society. International Forum for Logotherapy, 15, 66-7.

Halbesleben, J. R. B. 2010. A meta-analysis of work engagement: Relationships with burnout, demands, resources, and consequences. In A. B. Bakker (Ed.) \& M. P. Leiter, Work Engagement: A Handbook of Essential Theory and Research (pp. 102-117). New York, NY, US: Psychology Press.

Huhtala, H., \& Parzefall, M.-R. 2007. A review of employee well-being and innovativeness: An opportunity for a mutual benefit. Creativity and Innovation Management, 16(3), 299-306.

Luthans, F. 2002. The need for and meaning of positive organizational behavior. Journal of Organizational Behavior, 23: 695-706. 
Markos, S. and Sridevi, M.S. 2010. Employee Engagement: The Key to Improving Performance. International Journal of Business and Management, 5, 89-96.

Mazzetti, G., Schaufeli, W., Guglielmi, D. \& Depolo, M. 2016. Overwork climate scale: psychometric properties and relationships with working hard. Journal of Managerial Psychology, 31(4), pp. 880-896.

Meyer, J. P., Gagné, M., \& Parfyonova, N. M. 2012). Toward an evidence-based model of engagement: What we can learn from motivation and commitment research. In S. L. Albrecht (Ed.), New Horizons In Management. Handbook of Employee Engagement: Perspectives, Issues, Research And Practice (pp. 62-73). New York, NY, US: Psychology Press.

Rahmadani V.G., Schaufeli W.B., Ivanova T.Y., Osin E.N. 2019. Basic psychological need satisfaction mediates the relationship between engaging leadership and work engagement: A cross-national study. Human Resource Development Quarterly. In press.

Salanova, M., Rodríguez-Sánchez, A. M., Schaufeli, W. B., \& Cifre, E. 2014. Flowing together: A longitudinal study of collective efficacy and collective flow among workgroups. The Journal of Psychology, 148, 435-455.

Schaufeli, W.B. and Bakker, A.B. 2004. Job demands, job resources and their relationship with burnout and engagement: a multi-sample study. Journal of Organizational Behavior, 25(3), pp. 293-315.

Schaufeli, W. B., Salanova, M., González-Romá, V., \& Bakker, A. B. 2002. The measurement of engagement and burnout: A two sample confirmatory factor analytic approach. Journal of Happiness Studies, 3, 71-92.

Schaufeli, W. B., Bakker, A. B., \& Salanova, M. 2006. The measurement of work engagement with a short questionnaire. A cross-national study. Educational and Psychological Measurement, 66, 701-716.

Schaufeli, W. B., \& Bakker, A. B. 2010. Defining and measuring work engagement: Bringing clarity to the concept. In A. B. Bakker (Ed.) \& M. P. Leiter, Work Engagement: A Handbook of Essential Theory and Research (pp. 10-24). New York, NY, US: Psychology Press.

Schaufeli, W.B. 2012. Work engagement: What do we know and where do we go? Romanian Journal of Applied Psychology, 14, 3-10.

Schaufeli, W. B. (2015). Engaging leadership in the job demands-resources model. The Career Development International, 20, 446-463.

Schneider, B. Marcey, W.H \& Barbera, K.M. 2009. Driving customer satisfaction and financial success through employee engagement. People and Strategy, 32, 23-27.

Shuck, B. \& Herd, A.M. 2012. Employee engagement and leadership: exploring the convergence of two frameworks and implications for leadership development in HRD. Human Resources Management Review, 11(3), pp. 156-181.

Tims, M., Bakker, A. B., \& Xanthopoulou, D. 2011. Do transformational leaders enhance their followers' daily work engagement? Leadership Quarterly, 22, 121-131.

Torrente, P., Salanova, M., Llorens, S., \& Schaufeli, W. B. 2012. Teams make it work: How team work engagement mediates between social resources and performance in teams. Psicothema, 24, 106-12.

Van den Broeck, A., Vansteenkiste, M., De Witte, H., \& Lens,W. 2008. Explaining the relationships between job characteristics, burnout, and engagement: The role of basic psychological need satisfaction. Work \& Stress, 22,277-294. 